\title{
Autologous fat grafting after sarcoma surgery: Evaluation of oncological safety
}

\author{
Angela Pennati $^{\text {a }}$, Egidio Riggio $^{\mathrm{a}},{\text { Giuseppe } \text { Marano }^{\mathrm{b}} \text {, Elia Biganzoli }}^{\mathrm{b}, \mathrm{c}}$
}

a Unit of Plastic and Reconstructive Surgery, Fondazione IRCCS Istituto Nazionale dei Tumori, Via Venezian 1, 20133 Milano, Italy

b Laboratory of Medical Statistics, Biometry and Bioinformatics 'G. A. Maccacaro', Department of Clinical Science and Community Health, University of Milan, Campus Cascina Rosa, Fondazione IRCCS Istituto Nazionale dei Tumori, Via Vanzetti 5, 20133 Milano, Italy

c Unit of Medical Statistics, Biometry and Bioinformatics, Campus Istituto Nazionale dei Tumori, Via Vanzetti 5, 20133 Milano, Italy

Corresponding Author:

Egidio Riggio

Unit of Plastic and Reconstructive Surgery

Fondazione IRCCS Istituto Nazionale dei Tumori

Via Venezian 1, 20133 Milano, Italy

E-mail address: egidio.riggio@istitutotumori.mi.it 


\begin{abstract}
Background: The regenerative effectiveness of lipoaspirate procedures relies on the presence of mesenchymal stem cells, but the stromal microenvironment and hormonal secretions of the adipose tissue may be involved in cancer growth. Only few oncological outcome studies of fat grafting at the surgical site of malignant neoplasms of mesenchymal origin are available; none of these studies examined a series of sarcoma cases. Objectives: We analyzed outcome in terms of local or distant spread and overall survival to investigate the oncological safety of fat grafting in patients with sarcoma. Patients and methods: Sixty consecutive patients who had undergone 143 fat grafting procedures after surgical resection of bone and soft tissue sarcomas of the head, trunk, and limbs with clear resection margins were enrolled from 2004 to 2015 in our tertiary care center. A mul- tidisciplinary sarcoma team administered adjuvant therapies. Patients were recurrence free at fat grafting. Results: The overall median follow-up was 7.5 years. At followup after fat grafting (2.4 years), one patient had distant metastasis and two had local relapse. Kaplan-Meier analysis showed disease-free survival rate of 95.4\% (CI: 89.1-100.0) at 24 months. The risk of local recurrence (LR) within 24 months was 4.6\% (CI: 0.0-20.9). The probability of not having LR after fat grafting was $\geq 89.1 \%$.
\end{abstract}




\section{Introduction}

Bone and soft tissue sarcomas form a heterogeneous group of malignant neoplasms of mesenchymal origin accounting for $1 \%$ of all cancers. ${ }^{1}$ They comprise approximately 50 different types with different clinical behaviors and diverse, often unclear etiologies. The soft tissue sarcoma incidence rate is 2.4 per 100,000 per year in the general population, ${ }^{2}$ whereas bone sarcomas are approximately three times less frequent. Sarcomas affect all age groups but are more prevalent in people aged above 55 years. The main primary sites are the extremities (50-60\%), especially the legs, ${ }^{3}$ followed by the trunk, retroperitoneum, breast, and head and neck. Radiation-induced soft tissue sarcomas are rare (3\% of soft tissue sarcomas) and occur in the lung, esophagus, and breast, especially after Hodgkin lymphoma and breast cancer. ${ }^{4}$ Sarcomas can range from low-high-grade malignancy and may be associated with skip metastases. Lymph node metastases are rare (10\%), except for the synovial type (25\%). Distant metastases often occur in the lungs. The prognosis and treatment strategies depend on the histological type and grade and focus on early diagnosis, compartment surgery, and radiation therapy. ${ }^{5}$ Chemotherapy may also be used. Disease-specific survival rate is approximately $75 \%$. ${ }^{6,7}$ The local recurrence (LR) rate ranges from $4 \%$ to $39 \%$ at 5 years, depending on various factors. ${ }^{6-9}$ Resection with wide tumor- free margins is mandatory for a good prognosis. Radiation-induced sarcoma arises sporadically after an average latency period of 10 years and is particularly aggressive. Microscopically negative resection margins are difficult to achieve, and the LR rate is high, up to $65 \% .{ }^{10}$ The 5 year overall survival rate has been reported to be $41-$ $59 \% .{ }^{11,12}$ Currently, radical tumor resection does not necessarily involve morphological alteration and function loss because of reconstructive surgery with autologous flaps, tissue expanders, nerve and tendon transfers, and, most recently, lipofilling. Fat grafting (lipofilling) was repopularized at the turn of the century after the introduction of micro-fat-grafting and lipoaspirate-processing techniques. ${ }^{13,14}$ The effectiveness of lipoaspirate grafting relies on the presence of mesenchymal stem cells and their regenerative effect on extensive scarring or radiation damage of the skin and soft tissues. ${ }^{15}$ These mesenchymal progenitors of adipocytes secrete adipokines, angiogenic cytokines, and growth factors. Importantly, the number of stem cells in the lipoaspirate is much higher than that in the bone marrow. ${ }^{16}$ The multilineage differentiation capacity of adult stem cells is well known. ${ }^{17}$ In breast cancer, the stromal microenvironment with stromal cells and an adipose context of endocrine autocrine, paracrine, 
and exocrine secretions can contribute to cancer development, recurrence, and metastasis, but there is no evidence that stem cells are directly tumorigenic, i.e., able to induce the neoplastic transformation of normal cells. ${ }^{18-20}$ Evidence of the oncological safety of fat grafting after cancer surgery is based primarily on clinical studies in breast cancer and is limited by possible bias. Fat injection after mastectomy appears to be safe, but the correction of con- tour defects after conservative treatment of the breast re- mains controversial. ${ }^{21-24}$ The biology of sarcoma is quite different from that of breast carcinoma. The unclear and multifarious etiopathogenesis of sarcomas and the high risk of LR combined with the variable signaling of the fat microenvironment including adipose-derived stem cells and related growth factors should be investigated more extensively. Additionally, plastic surgeons should be aware of potential safety issues as these new microenvironments of fat are injected into a surgical bed where dormant neoplastic cells can survive even after correct cancer treatment. Unfortunately, reports of patients with sarcoma treated by fat grafting are anecdotal. Perrot et al. ${ }^{25}$ reported an unexpected local osteosarcoma recurrence 13 years after primary cancer treatment and 28-18 months after three sets of fat injection. This finding prompted the authors to investigate the behavior of mesenchymal stem cells from the human adipose tissue by injecting them in a murine model of human osteosarcoma. Their preclinical models showed that fat grafts or progenitor cells can promote tumor growth. The purpose of the present study was to analyze the oncological outcome after a series of 143 fat-grafting procedures at the surgical sites of former sarcoma resections. All patients in this study had presented with soft tissue and bone sarcomas. They were treated and followed for a 30 year period at our institute, one of the largest tertiary care sarcoma centers in Europe. We reported LRs, distant metastases, and overall survival of these patients after curative cancer treatment and investigated in particular the relationship between fat grafting and the risk of LR.

\section{Patients and methods}

Sixty-five patients who had undergone fat grafting between June 2004 and April 2015 to restore soft tissue defects af- ter resection of primary or recurrent sarcoma were con- sidered for inclusion in a consecutive series. Clinical data were extracted from clinical charts, prospective databases, and patients' consultation reports. We excluded one patient because of poor data quality and four patients because of the absence of follow-up data. The remaining 60 patients, for 
a total of 143 fat-grafting procedures (mean 2.38 per patient), were included in the study. They had undergone surgery for localized sarcoma between 1974 and 2011. The median age at disease presentation was $31.7 \pm 17.9$ years (range, 4 months to 66.9 years). The time of primary surgery was unknown in three cases. The tumor sites were maxillo- facial (10), head (3), limbs (17), trunk (18), breast (10), vagina (1), and perineal/anal area (1). In 18 cases, a surgical biopsy or partial excision had been carried out in the months before the major surgery. Tumor-free margins had been obtained in all cases. The series included only 25 out of more than 50 forms of sarcoma. Table 1 presents the histological types and their frequency. Twenty-three tumors were of low-grade malignancy, and 20 were of high-grade malignancy; grading was unknown in the earliest cases. The American Joint Committee on Cancer (AJCC) stage of dis- ease 26 at presentation to our institution, before fat grafting, was stage I in 19, stage II in 21, and stage III in three, and indefinite in the remaining 17 cases but with the exclusion of stage IV. There was only one lymph node metastasis in a supraclavicular node at first presentation in a child with a thoracic neuroblastoma. Surgery was supplemented with chemotherapy in 34 patients $(56.6 \%)$ and radiotherapy (45-70 Gy) in 35 patients (58.3\%). Head, limb, and breast resections were followed by plastic reconstructions, and limb-sparing techniques were used in primary surgery. In one case, limb hyper- thermic chemoperfusion was applied. The decision about chemotherapy and/or radiation was made by a multidisci- plinary sarcoma team or as part of ongoing clinical trials and varied during the long course of the study.

\section{Surgical procedure}

Fat grafting was performed after surgical resection with clear resection margins and adjuvant therapies according to tumor histology, patient age, and disease stage. The patients' mean age at first or only procedure was $38.8 \pm 15.0$ years (range, $13.9-71.7$ years). Fat was harvested by aspiration using a $3 \mathrm{~mm}$ cannula. The mean volume was $108 \pm 76.9 \mathrm{cc}$ (range, 12-440 cc); after Coleman's centrifu- gation 14 , the injected fat had a volume of $64.8 \pm 45.9 \mathrm{cc}$ (range, $3-180 \mathrm{cc}$ ). The fat amounts were measured in 107 of 143 procedures.

\section{Results}

The mean oncological follow-up time was more than 10 years, ranging from 19.6 months to approximately 40 years. The overall median follow-up time was 7.5 years. The median time 
before fat grafting was 3.9 years (range: $0.4-36.5$ ); in this period, the disease-free survival rate was $80 \%$ : two patients had a single metastasis (one supraclavicular node and one pleural node treated by metastasectomy) and 10 patients had LR (16.6\%) ( Table 2 ). The median disease- free interval before LR was 34 months. Only three patients had multiple LRs (two to five times). One thigh amputation was necessary owing to recurrent disease. The median disease-free time from LR to fat grating was 52 months. Our study focused on LR after fat grafting, i.e., after the first or only procedure. The observation time from fat graft- ing to LR or last follow-up ranged from 2.2 to 85.5 months ( 7.1 years), with a median of 28.6 months (2.4 years). Dur- ing this period, LR after fat injection was recorded in two patients ( Table 3 ). In the first patient (affected by a desmoid tumor, an aggressive soft tissue sarcoma of the extremities), the onset of LR was immediate and multiple, at 2.4 and 14 months; in the second patient (with Ewing's sarcoma) LR occurred at 23.4 months. The first patient had a history of LR before fat grafting; the second patient had a disease- free interval of 168 months after primary cancer treatment. Only one distant relapse was recorded (lung metastasis with death 2 years after fat grafting). The series does not report exitus not-related to sarcoma-specific mortality. The overall disease-free survival rate was $80 \%$ in the period preceding fat grafting and decreased in the years after fat grafting. In fact, the overall disease-free survival was $76.6 \%$ along all the 7.5 years of total median followup.

\section{Statistical analysis}

Descriptive statistics were reported as median (range) or as the percentage of patients with the characteristics. Because of the small number of patients developing LR $(n=2)$ and the relatively limited follow-up time, Kaplan-Meier analysis of the survival probability was the best option to assess the risk of LR following fat grafting after sarcoma surgery. Based on the observed results, the survival probability estimates were assessed for a maximum of 24 months. The diagram in Figure 1 depicts the estimates of the disease-free survival function with $95 \%$ confidence intervals (CIs). At 24 months, the value of the survival function was 95.4\% (CI 89.1-100.0). This means that the probability of not having LR after fat grafting was significantly higher than $89.1 \%$. Conversely, the risk of LR within 24 months was 4.6\% (CI 0.0-20.9).

\section{Discussion}


Soft tissue sarcomas of the trunk, limbs, and breast were the most common in our study population. The disease-free survival rate was $80 \%$ at 4 years after surgical resection (be- fore fat grafting) and $75 \%$ in the entire period of 7.5 years. In a Kaplan-Meier analysis of 543 sarcomas of the trunk reported by Wilder et al., ${ }^{27}$ the disease-specific survival after surgery was $83 \%$ at 5 years and $74 \%$ at 10 years. The recurrence rates after resection were significantly worse for patients with breast and chest wall tumors: 5 years after surgery, LR had occurred in $21 \%$ of patients with breast tumors and $23 \%$ of patients with chest wall tumors. At our own institution, Gronchi et al. ${ }^{7}$ observed a series of 1094 adult patients who were treated for localized soft tissue sarcomas of the extremities for a period of 20 years with a median follow-up time of 81 months; they found that the 5 year LR rate and cause-specific death incidence declined from $15 \%$ and $23 \%$ in the period $1987-1992$ to $6 \%$ and $9 \%$, respectively, in the period 2003-2007. In the latter period, preoperative combined chemoradiation therapy was introduced and administered to $12 \%$ of patients. The authors considered competitive risks, but their crude cumulative incidence is not directly comparable with the probability of LR after fat grafting estimated by us. The diseasespecific survival rate after lipofilling in the present study was $95.4 \%$, and only one sarcomaspecific death occurred. The exclusion of patients with a dismal prognosis and distant metastases as candidates for lipofilling may explain the low mortality. The mortality, and probably also the risk of recurrent disease, is low in our study population because the treated patients were free from dis- ease at the time of selection for fat grafting. Distant metastases (pleuropulmonary) occurred 2 years after soft tissue sarcoma primary surgery in two patients; one treated by metastasectomy and the other by sternothoracotomy and extensive resection. Of 1017 patients treated at our institution for soft tissue sarcomas of the extremities, 238 were also treated for their first LR, with significant worsening of their prognosis. ${ }^{28}$ To the best of our knowledge, this study is the first to assess the hazards of fat grafting in a restricted population affected by a rare and peculiar tumor type such as sarcoma. After a median time of approximately 4 years from cancer surgery, fat grafting was associated with a moderately low risk of LR ( $4.6 \%$ in 2 years), albeit with a CI of $20.9 \%$. In particular, our study strengthens the positive findings about the possible secondary effects of fat grafts in the breast, a much-debated issue in the literature. Ten patients having seven different histological tumor types were treated with fat injections, the most common type of tumor being angiosarcoma with three cases. Only one LR was reported in a phyllodes tumor, but before fat grafting. Our findings therefore suggest that fat grafting -with its 
biological implications - should be considered as onco- logically safe. The number of patients with relapses (three out of more than 60: one distant and two local) suggests a low risk. The patient with the recurrent desmoid tumor had a history of multiple LRs before fat injection and was disease free for 2.4 months between LR and fat grafting. The subsequent LR can reasonably be attributed to the inherently higher local malignancy of desmoid tumors rather than to cancer growth stimulation by stromal cells and growth factors in the fat grafts. A recent meta-analysis found an overall recurrence rate of $25.1 \%$ in patients with primary disease and $46.3 \%$ in patients with recurrent desmoid-type fibromatosis. ${ }^{29}$ The only discordant datum is the short interval of 3 months from the previous surgery for LR (thigh amputation) and fat injection. In the other nine patients with earlier LR, fat grafting was performed 10-204 months after LR occurrence and treatment. Another sarcoma with high LR rates and no risk of distant metastases is dermatofibrosarcoma protuberans (DFSP). LRs have been found to occur between 3 and 5 years after resection in more than $20 \%$ of patients. 30 In our series, two of seven patients developed LR, but we did not find any recurrent disease in patients who had undergone fat injection procedures after disease-free intervals of 17 and 44 months after LR. Our study included seven patients affected by DFSP, two of whom with LR before fat grafting and none after. The second case of LR after fat injection was a 10 year-old child with Ewing's sarcoma of the hip treated by primary chemotherapy, surgery, and radiotherapy. The remarkably invasive and very late-onset LR (168 months after surgery) occurred 24 months after the first four fat graftings and nine months after the last. This event is highly unexpected after complete remission. In a study by Bacci et al. ${ }^{31}$, 98.6\% of LRs occurred within 10 years of primary treatment in a group of 402 patients with nonmetastatic Ewing's sarcoma; during a mean follow-up of 18 years, the mean time to relapse was 28.1 months (range, 2-240 months) and only one LR was re- ported between 11 and 15 years. The case of this child shows similarities with the above- mentioned case report by Perrot et al. 25 of LR occurring 13 years after primary treatment of a telangiectatic osteosarcoma of the humerus; LR was detected at 28 and 18 months, respectively, after the first and last of three fat-injection procedures. Neither our case nor Perrot's showed any pre- dictive factors for LR, with wide surgical margins being obtained and multimodality therapy being given in both cases. When Perrot et al. subsequently investigated the correlation between fat injections and human osteosarcoma growth in immunodeficient mice, they found that fat injections promoted the growth of osteosarcoma cells. The mesenchymal stem cells differentiated into 
osteoblasts and adipocytes as well as muscle cells of vascular smooth muscle lineage. There is no evidence that adult stem cells or mesenchymal stem cells are tumorigenic per se, although liposarcomas contain an aggressive multipotent malignant cell population similar to adult stem cells. ${ }^{32}$ The safety of lipofilling should be investigated in relation to late disease progression because the interaction between an adipose tissue microenvironment, adult stem cells, and tumor cell growth is not immediate, and if there is any tumorigenic effect, it will take months or years for it to be- come macroscopically evident. The connection between inflammation and tumorigene- sis through intrinsic and extrinsic pathways 33 could also con- tribute to the late onset of LR. In our case, a chronic inflammatory microenvironment generated by fat grafting into the tumor bed might have activated an extrinsic pathway to LR. Several lines of evidence indicate that inflammation is im- plicated in sarcomagenesis through the activation of the key transcription factors NF- $\kappa \mathrm{B}$, STAT-3, and HIF-1, which are in- volved in a complex inflammatory network. 34 Additional questions to investigate are whether fat injections are determinants in the clock-like mechanism that controls the angiogenic switch of dormant sarcoma cells and whether inhibitors of proinflammatory pathways are able to control the behavior of fat grafts in the tumor bed of resected osteosarcomas and Ewing's sarcomas.

\section{Conclusions}

The rarity, histological heterogeneity, different age groups, and diverse anatomical sites of bone and soft tissue sarco- mas complicate the analysis of outcomes. In addition, basic and translational research into the association of the fat microenvironment, adipose-derived stem cells, and related growth factors is faced with the challenge of the unclear and multifarious etiology of sarcomas. According to our results, fat grafting seems to be a safe procedure in sarcoma patients, even though some caution is required. A waiting time of at least 12 months between the latest oncological surgery and this type of reconstructive procedure should be included in the treatment planning when there is a high risk of immediate relapse. A stimulatory role of fat injected into the tumor bed cannot be excluded in bone sarcoma even after a long period of remission. Our findings highlight the need for further studies with longer follow-up and larger series of patients from specialized cancer centers. 


\section{Acknowledgment}

We gratefully acknowledge the support of Mrs. Daniela Ma- jerna and Marije de Jager for editing the manuscript.

\section{References}

1. Kransdorf MJ . Malignant soft-tissue tumors in a large referral population: distribution of diagnoses by age, sex, and location. Am J Roentgenol 1995; 164 :129-34.

2. Wibmer C, Leithner A, Zielonke N, Sperl M, Windhager R . In- creasing incidence rates of soft tissue sarcomas? A popula- tion-based epidemiologic study and literature review. Ann Oncol 2010; $21: 1106-11$.

3. Morrison BA . Soft tissue sarcomas of the extremities. Proceed- ings (Bayl Univ Med Cent) 2003; $16(3): 285-90$.

4. Yap J , Chuba PJ, Thomas R, et al. Sarcoma as a second malig- nancy after treatment for breast cancer. Int J Radiat Oncol Biol Phys 2002; 52 :1231-7.

5. Pisters PW, Leung DH, WoodruffJ , Shi W, Brennan MF . Analysis of prognostic factors in 1,041 patients with localized soft tissue sarcomas of the extremities. J Clin Oncol 1996; 14 :1679-89 .

6. Stoeckle E, Gardet H, Coindre JM, et al. Prospective evaluation of quality of surgery in soft tissue sarcoma. Eur J Sur Oncol 2006; 32 :1242-8 .

7. Gronchi A, Miceli R, Colombo C, et al. Primary extremity soft tissue sarcomas: outcome improvement over time at a single institution. Ann Oncol 2011; 22 :1675-81 .

8. Trovik CS , Bauer HCF , Alvegard TA, et al. Surgical margins, lo- cal recurrence and metastasis in soft tissue sarcomas: 559 sur- gically-treated patients from the Scandinavian Sarcoma Group Register. Eur J Cancer 2000; 36 :710-16.

9. Cahlon O, Spierer M, Brennan MF, Singer S, Alektiar KM . Long-term outcomes in extremity soft tissue sarcoma after a pathologically negative re-resection and without radiotherapy. Cancer 2008; $112: 2774-9$.

10. Neuhaus SJ , Pinnock N, Giblin V, et al. Treatment and outcome of radiation-induced softtissue sarcomas at a specialist insti- tution. Eur J Surg Oncol 2009; 35 :654-9.

11. Cha C, Antonescu CR, Quan ML, Maru S, Brennan MF . Long-term results with resection of radiation-induced soft tissue sarco- mas. Ann Surg 2004; 239 :903-10 . 
12. Vorburger SA, Xing Y, Hunt KK, et al. Angiosarcoma of the breast. Cancer 2005; 104 :2682-8 .

13. Bircoll M . Cosmetic breast augmentation utilizing autolo- gous fat and liposuction techniques. Plast Reconstr Surg 1987; 79 :267-71 .

14. Coleman SR . Long-term survival of fat transplants: controlled demonstrations. Aesthet Plast Surg $1995 ; 19: 421-5$.

15. Rigotti G, Marchi A, GalièM, et al. Clinical treatment of ra- diotherapy tissue damage by lipoaspirate transplant: a healing process mediated by adipose-derived adult stem cells. Plast Reconstr Surg 2007; $119: 1409-24$.

16. Kern S , Eichler H, Stoeve J , Klüter H , Bieback K . Comparative analysis of mesenchymal stem cells from bone marrow, umbili- cal cord blood, or adipose tissue. Stem Cells 2006; 24 :1294-301.

17. Zuk PA, Zuh M, Ashjian P, et al. Human adipose tissue is a source of multipotent stem cells. Mol Biol Cell 2002; 13 :4279-95 .

18. Karnoub AE, Dash AB , Vo AP, et al. Mesenchymal stem cells within tumour stroma promote breast cancer metastasis. Na- ture 2007; 449 :557-63 .

19. Pinilla S , Alt E , Abdul Khalek FJ , et al. Tissue resident stem cells produce CCL5 under the influence of cancer cells and thereby promote breast cancer cell invasion. Cancer Lett 2009; 284 : 80-85 .

20. Muehlberg FL, Song YH, Krohn A, et al. Tissue-resident stem cells promote breast cancer growth and metastasis. Carcino- genesis 2009; 30 :589-97 .

21. Krastev TK, Jonasse Y, Kon M . Oncological safety of autologous lipoaspirate grafting in breast cancer patients: a systematic re- view. Ann Surg Oncol 2013; 20 :111-19 .

22. Petit JY, Rietjens M , Botteri E, et al. Evaluation of fat graft- ing safety in patients with intraepithelial neoplasia: a matched cohort study. Ann Oncol 2013; 24 :1479-84 .

23. Riggio E , Bordoni D , Nava MB . Oncologic surveillance of breast cancer patients after lipofilling. Aesthet Plast Surg 2013; $37: 728-35$.

24. Gale KL, Rakha EA, Ball G, Tan VK, McCulley SJ , Macmillan RD . A case-controlled study of the oncologic safety of fat grafting. Plast Reconstr Surg 2015; $135: 1263-75$.

25. Perrot P, Rousseau J , Bouffaut AL, et al. Safety concern be- tween autologous fat graft, mesenchymal stem cell and os- teosarcoma recurrence. PLoS One 2010; 5 :e10999. 
26. Edge SB , Byrd DR, Compton CC, Fritz AG, Greene FL, Trotti A . American Joint Committee on Cancer (AJCC) Cancer Staging Manual . 7th ed. Chicago, IL: Springer, Inc.; 2010

27. Wilder F, D'Angelo S, Crago AM . Soft tissue tumors of the trunk: management of local disease in the breast and chest and abdominal walls. J Surg Oncol 2015; $111: 546-52$.

28. Gronchi A, Miceli R, Fiore M, et al. Extremity soft tissue sar- coma: adding to the prognostic meaning of local failure. Ann Surg Oncol 2007; 14 :1583-90 .

29. Janssen ML, van Broekhoven DL, Cates JM, et al. Meta-analysis of the influence of surgical margin and adjuvant radiotherapy on local recurrence after resection of sporadic desmoid-type fibromatosis. Br J Surg 2017; 104 :347-57 .

30. Bowne WB , Antonescu CR, Leung DH , et al. Dermatofi- brosarcoma protuberans: a clinicopathologic analysis of pa- tients treated and followed at a single institution. Cancer 2000; $88: 2711-20$.

31. Bacci G, Forni C, Longhi A, et al. Long-term outcome for patients with non-metastatic Ewing's sarcoma treated with adjuvant and neoadjuvant chemotherapies. Eur J Cancer 2004; 40 :73-83.

32. Zhang Y, Young ED, Bill C, et al. Heterogeneity and immunophe- notypic plasticity of malignant cells in human liposarcomas. Stem Cell Res 2013; 11 :772-81.

33. Mantovani A, Allavena P, Sica A, et al. Cancer-related inflam- mation. Nature 2008; 454 :436-44.

34. Radons J . The role of inflammation in sarcoma. Adv Exp Med Biol 2014; 816 :259-313 . 
Table 1 Cancer Histology (Total: 60 tumors).

\begin{tabular}{|c|c|c|c|c|c|c|c|c|c|c|c|}
\hline $\begin{array}{l}\text { Fibroblastic } \\
\text { sarcoma } \\
n=11\end{array}$ & $\begin{array}{l}\text { Rhabdomyo } \\
\text { sarcoma } \\
n=6\end{array}$ & $\begin{array}{l}\text { Liposarcoma } \\
n=6\end{array}$ & $\begin{array}{l}\text { Pleomorphic } \\
\text { sarcoma } \\
n=6\end{array}$ & $\begin{array}{l}\text { Synovial } \\
\text { sarcoma } \\
\mathrm{n}=5\end{array}$ & $\begin{array}{l}\text { Spindle cell } \\
\text { sarcoma } \\
n=3\end{array}$ & $\begin{array}{l}\text { Angio } \\
\text { sarcoma } \\
n=3\end{array}$ & $\begin{array}{l}\text { Leiomyo } \\
\text { sarcoma } \\
\mathrm{n}=2\end{array}$ & $\begin{array}{l}\text { Bones } \\
\text { sarcoma } n=6\end{array}$ & $\begin{array}{l}\text { Epithelioid } \\
\text { sarcoma } \\
n=1\end{array}$ & $\begin{array}{l}\text { Other tumors } n \\
=6\end{array}$ & $\begin{array}{l}\text { Embryonal } \\
\text { tumors } \\
\mathrm{n}=5\end{array}$ \\
\hline $\begin{array}{l}\text { DFSP } 7 \\
\text { Myxofibro- } \\
\text { sarcoma } 4\end{array}$ & $\begin{array}{l}\text { Embryonal } 3 \\
\text { Classic } \\
\text { variant } 2 \\
\text { Botryoid type } 1\end{array}$ & $\begin{array}{l}\text { Myxoid } 4 \\
\text { Pleomorphic } 1 \\
\text { Lipoma-like } 1\end{array}$ & 6 & 5 & $\begin{array}{l}\text { Classic } \\
\text { variant } 2 \\
\text { Epithelioid } \\
\text { pleomorphic } \\
\text { variant } 1\end{array}$ & 3 & $\begin{array}{l}\text { Pleomorphic } 1 \\
\text { Classic } \\
\text { variant } 1\end{array}$ & $\begin{array}{l}\text { Osteosarcoma } \\
2 \\
\text { Ewing/PNET } 4\end{array}$ & 1 & $\begin{array}{l}\text { Malignant } \\
\text { Phyllodes } 2 \\
\text { Ewing/PNET } 2 \\
\text { Aggressive } \\
\text { Fibromatosis } 1 \\
\text { Langerhans cell } \\
\text { Histiocytosis }\end{array}$ & $\begin{array}{l}\text { Retinoblastoma } \\
3 \\
\text { Ganglioneuro } \\
\text { blastoma } 1 \\
\text { Neuroblastoma } \\
1\end{array}$ \\
\hline
\end{tabular}


Table 2

Patients with locoregional recurrence before lipofilling.

\begin{tabular}{|c|c|c|c|c|c|c|c|c|c|c|c|}
\hline Case & $\begin{array}{l}\text { First } \\
\text { surgery }\end{array}$ & LR (No.) & $\begin{array}{l}\text { Last } \\
\text { surgery/ } \\
\text { therapy }\end{array}$ & Histotype & Grading & Site & $\begin{array}{l}\text { Distant } \\
\text { metastasis }\end{array}$ & $\begin{array}{l}\text { Disease- } \\
\text { free time } \\
\text { before LR } \\
\text { (months) }\end{array}$ & $\begin{array}{l}\text { Disease- } \\
\text { free time } \\
\text { from LR } \\
\text { to } \\
\text { lipofilling } \\
\text { (months) }\end{array}$ & $\begin{array}{l}\text { Lipofilling } \\
\text { Session } \\
\text { (No.) }\end{array}$ & $\begin{array}{l}\text { Overall } \\
\text { Follow-up } \\
\text { (months) }\end{array}$ \\
\hline 1 & 1978 & 5 & 2011 & Osteosarcoma & High & $\begin{array}{l}\text { Maxillary } \\
\text { bone }\end{array}$ & 0 & 204 & 33 & 1 & 429 \\
\hline 2 & 1991 & 1 & 2002 & $\begin{array}{l}\text { Ewing's } \\
\text { sarcoma/PNET }\end{array}$ & High & Trunk & 0 & 120 & 91 & 3 & 282 \\
\hline 3 & 2005 & 1 & 2007 & Dermatofibrosarcoma & Low & Trunk & 0 & 27 & 27 & 1 & 110 \\
\hline 4 & 1996 & 1 & 1999 & Leiomyosarcoma & High & Breast & 0 & 41 & 119 & 2 & 279 \\
\hline 5 & 2009 & 1 & 2010 & Pleomorphic sarcoma & High & Limb & 0 & 17 & 17 & 2 & 65 \\
\hline 6 & 2007 & 1 & 2008 & Dermatofibrosarcoma & Low & Trunk & 0 & 10 & 44 & 2 & 84 \\
\hline 7 & 1982 & 4 & 2007 & $\begin{array}{l}\text { Aggressive } \\
\text { fibromatosis }\end{array}$ & Low & Limb & 0 & 4 & 3 & 1 & 325 \\
\hline 8 & 2000 & 2 & 2005 & $\begin{array}{l}\text { Langerhans cell } \\
\text { histiocytosis }\end{array}$ & $\mathrm{n} / \mathrm{a}$ & $\begin{array}{l}\text { Cranio- } \\
\text { maxillo- } \\
\text { facial } \\
\text { region }\end{array}$ & 0 & 22 & 60 & 5 & 179 \\
\hline 9 & 1992 & 1 & 1997 & Rabdomyosarcoma & $\mathrm{n} / \mathrm{a}$ & Neck & 0 & $\mathrm{n} / \mathrm{a}$ & 120 & 10 & 204 \\
\hline 10 & 2004 & 1 & 2009 & Malignant Phyllodes & Low & Breast & 0 & 60 & 64 & 2 & 130 \\
\hline
\end{tabular}


Figure 1

Disease specific survival

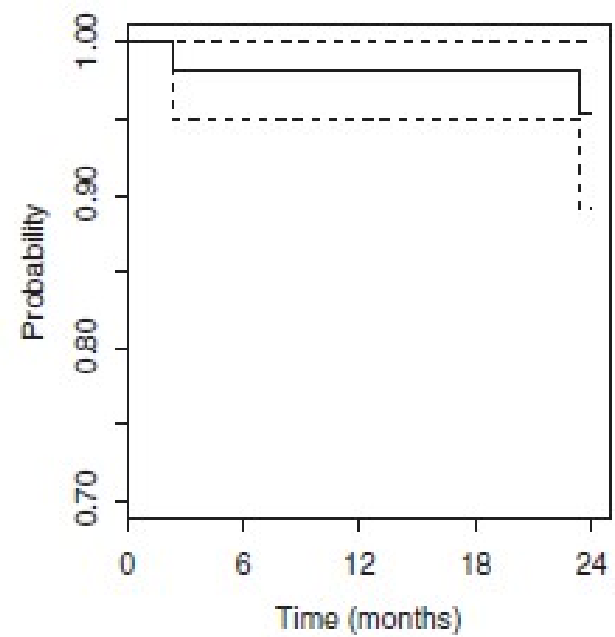

